reconhecer situações antecedentes ao trabalho que possam gerar ou induzir ao deslocamento de sentido tanto do prazer como do sofrimento dos trabalhadores de enfermagem no seu processo de trabalho; estabelecer parâmetros para discriminação entre o sofrimento real e o deslocado em seu sentido, dentre aqueles descritos pelos trabalhadores de enfermagem; evidenciar as formas encontradas pelos trabalhadores de enfermagem na produção de deslocamento de sentido do prazer ou sofrimento no trabalho, contribuindo para o aprofundamento reflexivo da temática. A análise teve por base quatro matrizes construídas a partir dos mitos de Apolo, Prometeu, Dioniso e Narciso. O estudo evidenciou a afirmação contida na tese, embora a dificuldade encontrada pela não percepção das pessoas, que poucas vezes param para pensar em questão como esta. Mostrou, também, que o cotidiano destes trabalhadores é atribulado pelo ritmo intenso imposto pela necessidade de conciliar mais de um trabalho, pela corrida frenética na tentativa de não deixar nada para trás, para atender as exigências da educação dos filhos, da manutenção do relacionamento afetivo, para honrar os compromissos financeiros assumidos, entre tantas outras coisas, próprias da vida destes homens e mulheres que compõe o quadro de pessoal da enfermagem. Aponto para a necessidade de construção de uma práxis reflexiva, relativa ao sofrimento e ao prazer no trabalho da enfermagem que, acredito, configura-se como uma possibilidade concreta para a vivência destas sensações no trabalho e na vida, de modo geral, tirando as pessoas da inconsciência em relação aos seus próprios sentimentos e permitindo que se estabeleça uma relação mais objetiva entre o sofrimento da vida social e o sofrimento da vida social do trabalho.

\title{
ENFERMERA, TRABAJO Y RESISTENCIA: EL SIGNIFICADO DE LA ESPERANZA: EL CASO DEL CEARÁ, BRASIL
}

Autora: Silvia Maria Nòbrega-Therrien

Orientador: Mariano Fernández Enguita

RESUMO: Las contribuciones de investigaciones socio históricas que estudian el trabajo y los trabajadores pueden surgir a partir de los clásicos que abordan este aspecto socio histórico y que pasa por Max, Engels, Weber, hasta Hobsbawa, Braverman y Thompson, entre muchos otros, sobretodo sociólogos e historiadores. Las investigaciones sobre el trabajo y más especificamente las estrategias colectivas o individuales de defensas, resistencias desarralladas por los trabajadores, presentan grande intéres para la comprensión del tema en cuestión. La forma por la cual los trabajadores o escapan de la explotación y dominación, ofrece subsidios para estúdios comparativos, pues la dominación y explotatción en los trabajos ocurre en diferntes contextos y socio culturales. Estas formas como también los contextos, por acrescentar diferencias, , nuevas dimensiones.

\section{PRAZER E O SOFRIMENTO NO COTIDIANO DO ENFERMEIRO DE CENTRO CIRÚRGICO}

\author{
PRAZER E O SOFRIMENTO NO COTIDIANO DO ENFERMEIRO DE CENTRO CIRÚRGICO \\ PRAZER E O SOFRIMENTO NO COTIDIANO DO ENFERMEIRO DE CENTRO CIRÚRGICO
}

Autora: Mônica Krahl

Orientadora: Rosita Saupe

\begin{abstract}
RESUMO: Las contribuciones de investigaciones socio históricas que estudian el trabajo y los trabajadores pueden surgir a partir de los clásicos que abordan este aspecto socio histórico y que pasa por Max, Engels, Weber, hasta Hobsbawa, Braverman y Thompson, entre muchos otros, sobretodo sociólogos e historiadores. Las investigaciones sobre el trabajo y más especificamente las estrategias colectivas o individuales de defensas, resistencias desarralladas por los trabajadores, presentan grande intéres para la comprensión del tema en cuestión. La forma por la cual los trabajadores o escapan de la explotación y dominación, ofrece subsidios para estúdios comparativos, pues la dominación y explotatción en los trabajos ocurre en diferntes contextos y socio culturales. Estas formas como también los contextos, por acrescentar diferencias, también se diferencian. En Basil, surgió uma avalancha de trabajos en las áreas de sociología y psicología, así como en el campo de las ciencias sociales, como los de Brandão (1964), Leite-Lopes (1978), que tienen aportado contribuciones significativas para los análises sobre el trabajo y el trabajador uma vez que buscan compreender la resistência de estos en la lucha contra la dominación y exploración. Son estudios que tiene la fábrica como locus de investigación. En el área de la salud de los trabajadores, se destacan los estudios de Laurel (1983), Laurel y Noriega (1989), Carvalho (1988), Minayo (1986) y Seligmann-Silva (1994). Las investigaciones hechas en el área especifica de infermeria ya fueron citadas y se
\end{abstract}

